\title{
Analysis of a Boost PFC Pre-regulator Operated in both CRM and DCM
}

\author{
Gao Jiabao \\ College of Applied Science and Technology,Hainan University HaiNanDanZhou 571730.China \\ gaoj_jb@163.com
}

Keywords: PFC; Boost; NCP1601; CRM; DCM

\begin{abstract}
PFC (Power Factor Correction) power supplies are required to provide high input power factor and tight output voltage regulation [1]. Through analyzing the characteristics of various PFC converter modes, this paper is about the design and simulation of a boost PFC pre-regulator. This boost PFC pre-regulator takes advantage of both CRM(Critical Conduction Mode) and DCM(Discontinuous Conduction Mode) operating modes that can help to simplify the front-ended filter design, to reduce the costs and to improve the reliability of the circuit. Andthis paper presents a 100W PFC circuit and the computation methods of essential circuit parameters. The experimental results prove that the PFC circuit has the following characteristics:simple circuit, convenient debugger, high power factor, reliable and stable work.
\end{abstract}

\section{Introduction}

The issue of how to increase the efficiency of electronic power systems has been attracting more and more attention in recent years. Power grid connects more and more electronic equipments which employ rectifier in large scale. Therefore, harmonic pollution of power grid has emerged.

The traditional means of ac-to-dc conversion involves a rectifier followed by a large filter capacitor which can produce a dc voltage from the utility ac line. This technique is well-understood, simple and inexpensive. However, the line delivers no current until the line voltage is close to a maximal value and the effect of harmonic currents reduces the efficiency of the electric power system.

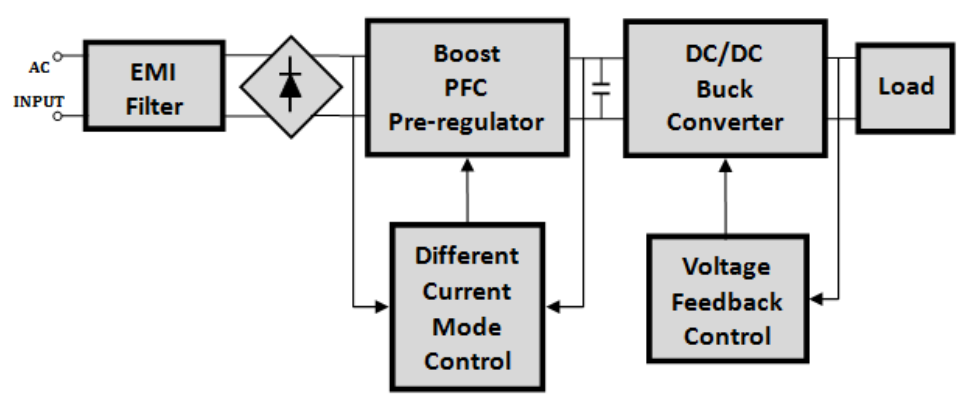

Fig.1 Two-stage PFC power supply circuit topology

For PF, if both current and voltage are sinusoidal and in phase, the PF is 1.0. If both are sinusoidal but not in phase, the power factor is the cosine of the phase angle. However, PFC converter forces the input current to follow the input voltage that results in a unity power factor. PFC can be modeled in many approaches [2]. A block diagram of the two-stage PFC power supply is depicted in Fig.1.

In order to improve PF, APFC (Active Power Factor Correction) technologies are employed in equipments widely. As a result of boost converter's special merit, it gets many applications in low power single-phase PFC systems [3]. The boost converter can operate in various modes such as CCM (Continuous Conduction Mode), DCM and CRM. The comparisons between different PFC converter modes and the description of them are showed in Table.1. 
Table.1 Analyze and compare different characteristics of PFC converter modes

\begin{tabular}{|c|c|c|}
\hline Waveform & $\begin{array}{c}\text { PFC Converter } \\
\text { Modes }\end{array}$ & Characteristic \\
\hline "Non onc & $\begin{array}{c}\text { Continuous } \\
\text { Conduction Mode } \\
\text { (CCM) }\end{array}$ & $\begin{array}{l}\text { Hard- } \\
\text { Switching } \\
\text { Large } \\
\text { inductance } \\
\text { Low virtual } \\
\text { value of } \\
\text { current } \\
\end{array}$ \\
\hline$\frac{\text { and of }}{\text { on }}$ & $\begin{array}{c}\text { Discontinuous } \\
\text { Conduction Mode } \\
\text { (DCM) }\end{array}$ & $\begin{array}{l}\text { High virtual } \\
\text { value of } \\
\text { current } \\
\text { Reduce the } \\
\text { value of } \\
\text { inductance } \\
\text { Better stability }\end{array}$ \\
\hline Q. orr & $\begin{array}{l}\text { Critical Conduction } \\
\text { Mode } \\
(\mathrm{CRM})\end{array}$ & $\begin{array}{l}\text { Good virtual } \\
\text { value of } \\
\text { current } \\
\text { Variable-- } \\
\text { Frequency }\end{array}$ \\
\hline
\end{tabular}

The advantages of CRM and DCM are concluded in the above analysis. CRM can limit the maximum current of the boost stage diode, MOSFET and inductance. It reduces the costs and improves the reliability of the circuit. And DCM can limit the maximum switching frequency [4]. It simplifies the front-ended EMI filter design. So, a PFC pre-regulator operated in CRM and DCM modes can take advantages of both modes. Fig.2 illustrates waveforms of current in the PFC converter operated between CRM and DCM.

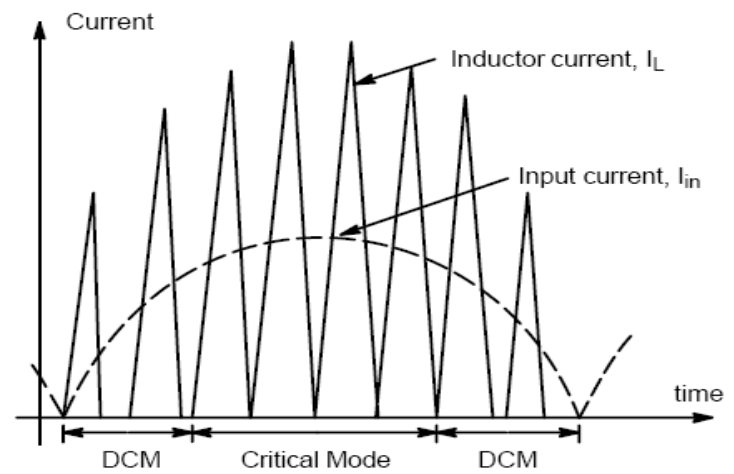

Fig.2 Waveforms of inductor current and input current between CRM and DCM

\section{Boost PFC Pre-Regulator Design Operates Between CRM And DCM}

Simulation Schematic and Description.This system substantially exhibits unity power factor while operating in both DCM and CRM [4]. The model of the constant on-time boost PFC pre-regulator is presented and simulated in Simulink. The main circuit schematic of this boost PFC pre-regulator is depicted in Fig. 3 and the basic principle are presented below. 


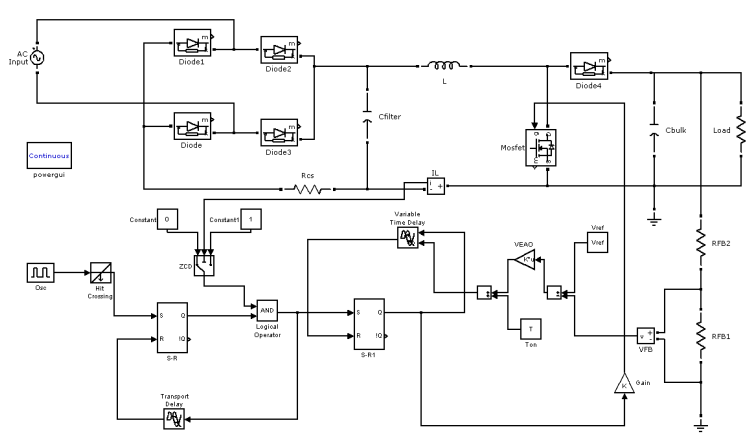

Fig.3 Schematic of a two-stage PFC power supply, with CCM/DCM boost pre-regulator under ACM and voltage feedback control

ZCD (Zero Cross Detection).For this simulation model, ZCD circuit includes a current ammeter and a ZCD switch. When inductance current falls to zero, ZCD switch can be turned on by the signal from the current ammeter and export a high voltage to make the current ramp up in CRM again. The time current from its maximum to zero is based on the input line voltage and the inductance, which also dictates the operating frequency range. Fig.4 shows the waveforms of inductor current and describes operating principle simply.

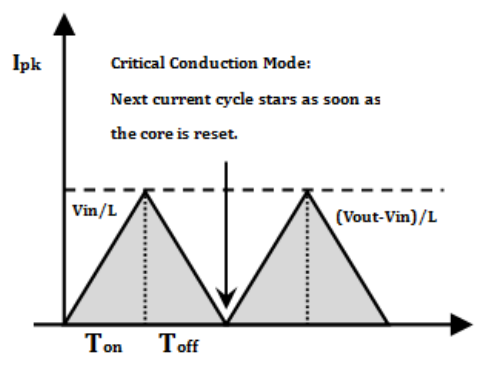

Fig.4 Waveforms of inductor current in CRM

OSC (Oscillator Mode).In order to keep the operation only in DCM or CRM, the Drive Output can not turn on as long as there is some inductor current flowing through the circuit. From the simulation model of OSC circuit, we can illustrate a typical timing diagram of the oscillator block in Fig.5 .

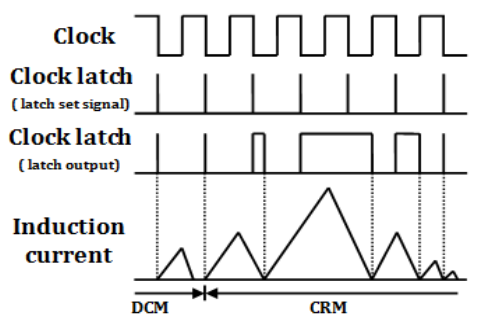

Fig.5 Timing diagram of the relationship between oscillator block and inductor current in CRM/DCM

So, this oscillator mode set the oscillator frequency of the DCM operation. If the inductance current is non-zero at the end of a switching period, the output drive is not allowed to turn on. CCM operation is prohibited. Instead, the circuit operates in CRM in this case [4].

Voltage Feedback. According to the simulation model of circuit (Fig.3), the Vout of this Boost PFC pre-regulator circuit is sensed by two feedback resistors RFB1 and RFB2. RFB is the feedback resistor connected between the Boost PFC pre-regulator circuit and the output voltage [5]. The feedback voltage VFB should be typically equal Vref that we set.

PWM (Pulse Width Modulator) Controller. The main components of this simulation model of PWM Controller circuit (Fig.3) include an adder, a Variable Time Delay and an S-R latch. The PWM comparator generates a duty cycle based on these two input signals. One is a constant time 
(Ton) which we set through the analysis about the right output voltage. The other is the error signal from Voltage Feedback Control. If Vout is lower than Vref that we design, the output of the adder will reduce and make the time when mosfet open descend through the S-R latch.

\section{Simulation Results and Discussions}

Due to the simulation results of the circuit, the input current waveform can follow the change of the input voltage. And the input current waveform of the CRM/DCM boost PFC pre-regulator is shown at Fig.6. Because of the variable frequency feature of the CRM and fixed frequency feature of DCM, switching frequency achieves the maximum in the DCM region and the minimum switching frequency will be found at the moment of the sinusoidal peak.

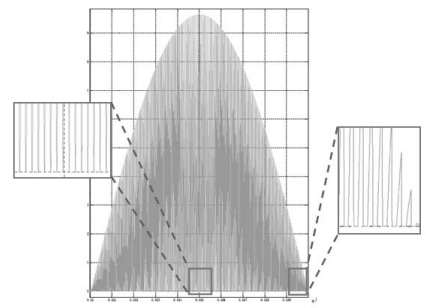

Fig.6 Present the different simulation waveforms of inductor current between CRM and DCM

\section{Description Of The Controller Nep1601}

The NCP1601 is a controller designed for PFC boost circuits. The device operates in fixed-frequency DCM and variable-frequency CRM. It takes advantages of both operating modes. This device substantially exhibits unity power factor while operating in DCM and CRM [4].

\section{The Design of the Key Circuit Parameters}

\section{The Main Design Goal Parameters [4]}

(1) Input Voltage: $85 \mathrm{Vac}-265 \mathrm{Vac} / 50 \mathrm{~Hz}$, the typical value is $220 \mathrm{~V}$.

(2) Output Voltage: $390 \mathrm{Vdc}$

(3) Output Power: $100 \mathrm{~W}$

(4) Switching frequency: Around $100 \mathrm{kHz}$

(5) Full Load Efficiency: $90 \%$

\section{The designed circuit schematic}

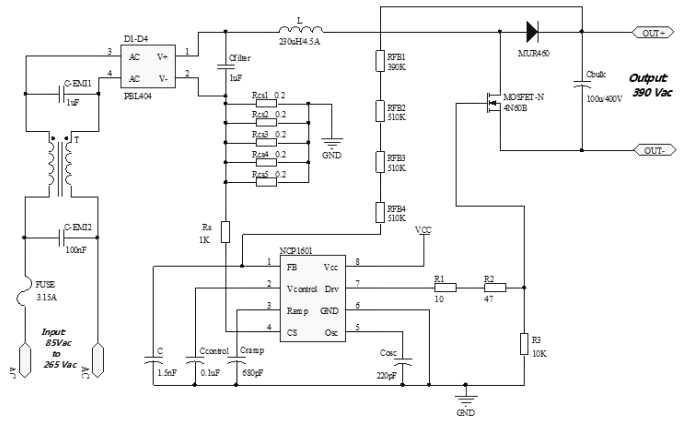

Fig.7 The sketch of 100W PFC circuit

The Design of the Key Components

i) Take an Assumption on Efficiency

The design assumes efficiency of this system as $90 \%$. Then, the input power Pin can be calculated as $111 \mathrm{~W}$. 


$$
\begin{gathered}
\eta=90 \% \\
P_{\text {in }}=\frac{P_{\text {out }}}{\eta}=\frac{100}{90 \%}=111 \mathrm{~W}
\end{gathered}
$$

This input power will be frequently used in the next few design steps.

ii) Calculate the Current Stress

The worst case input current rating happens when AC input voltage is $85 \mathrm{~V}$. The input RMS current $\mathrm{I}_{\mathrm{ac}}$ is $1.31 \mathrm{~A}$. The suffix ac denotes RMS value. This current stress is mainly on the front-ended rectifier [5].

$$
\mathrm{I}_{\mathrm{ac}}=\frac{\mathrm{P}_{\mathrm{in}}}{\mathrm{V}_{\mathrm{ac}}}=\frac{111}{85}=1.31 \mathrm{~A}
$$

The instantaneous maximum current stress in the PFC stage will be 3.7A in critical mode.

$$
\mathrm{I}_{\mathrm{pk}}=2 \sqrt{2} \cdot \mathrm{I}_{\mathrm{ac}}=3.7 \mathrm{~A}
$$

\section{iii) Oscillator Capacitor Design (Cosc)}

The switching frequency of this application can be set by oscillator. From the datasheet of NCP1601, we can set the frequency as $107 \mathrm{kHz}$ by a $100 \mathrm{pF}$ capacitor. Actually, this frequency is only valid for the DCM operation because CRM is with a lower switching frequency [5]. However, this frequency provides a reference on calculating the inductor for CRM in the next design step.

ix) Inductor Design (L)

The minimum inductor for CRM L (CRM) at low line is obtained as follows:

$$
\mathrm{L}_{\text {(CRM) }}=\frac{\mathrm{V}_{\text {out }}-\mathrm{V}_{\text {in }}}{\mathrm{V}_{\text {out }}} \cdot \frac{\mathrm{V}_{\text {in }}}{\mathrm{I}_{\mathrm{pk}}} \cdot \frac{1}{\mathrm{f}}=\frac{390 \mathrm{~V}-85 \times \sqrt{2} \mathrm{~V}}{390 \mathrm{~V}} \times \frac{85 \times \sqrt{2} \mathrm{~V}}{3.7 \mathrm{~A}} \times \frac{1}{107 \mathrm{kHz}}=210 \mathrm{uH}
$$

The maximum value of $\mathrm{L}(\mathrm{CRM})$ is at low line. Hence, a value is greater than $\mathrm{L}(\mathrm{CRM})$, which can make the circuit operate in CRM. The inductor $\mathrm{L}$ is therefore set at $230 \mathrm{uH}$, so the switching frequency $\mathrm{F}$ is $98 \mathrm{kHz}$, then the circuit operates in CRM.

$$
\mathrm{F}=\frac{\mathrm{V}_{\text {out }}-\mathrm{V}_{\text {in }}}{\mathrm{V}_{\text {out }}} \cdot \frac{\mathrm{V}_{\text {in }}}{\mathrm{I}_{\mathrm{pk}}} \cdot \frac{1}{\mathrm{~L}}=\frac{390 \mathrm{~V}-85 \times \sqrt{2} \mathrm{~V}}{390 \mathrm{~V}} \times \frac{85 \times \sqrt{2} \mathrm{~V}}{3.7 \mathrm{~A}} \times \frac{1}{230 \mathrm{uH}}=98 \mathrm{kHz}
$$

\section{Experiment waveforms and description}

Fig.8 illustrates the capability of both DCM and CRM operation of the NCP1601 .
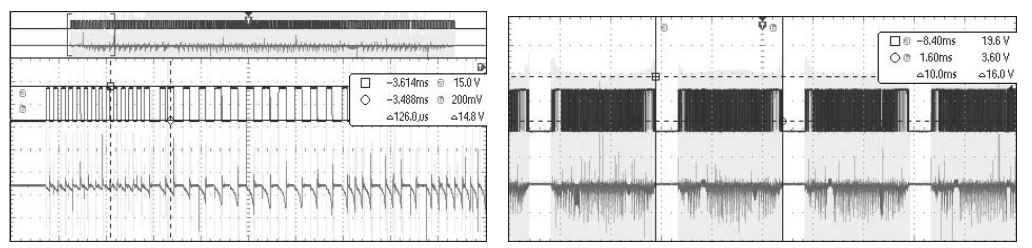

Fig. 8 The relationship between actual waveforms of PWM signal of PFC controller and inductor current

According to Fig. 8, this boost PFC pre-regulator works between CRM and DCM. Around zero current point, the system works in DCM and the oscillator frequency is set by the oscillator mode. With the increasing inductance current, if the inductance current is non-zero at the end of a switching period, the output drive is not allowed to be turned on. So, the PFC pre-regulator operates in the CRM.

\section{Conclution}


This paper presents a boost PFC method and its corresponding model, which operates in both CRM and DCM with nearly constant on-time. Simulation results and experimental results show that unity power factor can be achieved over wide input voltage and load current range. The voltage feedback compensation shows a good output voltage regulation and sinusoidal input current even when the input voltage is distorted. This Boost PFC circuit in CRM and DCM shows better and more accurate performance in both steady state (very low output voltage ripple) and transient state (low overshoot and drop) than in one PFC Converter Modes. Good power factor and line current THD in transient state are also achieved.

\section{Acknowledgements}

Hainan university college of applied science and technology (danzhou campus) school funded projects (Hyk - 1515)

\section{Reference}

[1] O. Dranga, G. Chu, C.K. Tse, Siu-Chung Wong, " Stability Analysis of Two-Stage PFC Power Supplies", PESC Record - IEEE Annual Power Electronics Specialists Conference 07/2006.

[2] ON Semiconductor Components Industries, "Power Factor Correction (PFC) Handbook", HBD853/D, Rev.3, Sept-2007.

[3] Yuandi Chen and Dichen Liu, "PFC research based on the new integrated controller" IEEE,2009

[4] ON Semiconductor Components Industries, "Compact Fixed Frequency Discontinuous or Critical Conduction Voltage Mode Power Factor Correction Controller", NCP1601A/D, Rev.4, Dec-2005.

[5] ON Semiconductor Components Industries, "100 Watt Universal Input PFC Boost Using NCP1601A", AND8182/D, Rev.1, Dec-2004. 